\title{
OPTIMALISASI TATA KELOLA TEKNOLOGI INFORMASI MENGGUNAKAN COBIT 5 (STUDI KASUS STT PAGAR ALAM)
}

\author{
Fitria Rahmadayanti ${ }^{1}$, Widya Cholil ${ }^{2}$, Linda Atika $^{3}$ \\ Magister Teknik Informatika \\ Universitas Bina Darma \\ ria.ria.rr71@gmail.com
}

Jl.A.Yani No.12, Palembang 30624, Indonesia

\begin{abstract}
Abstrak
Penelitian ini membahas tentang optimalisasi tata kelola teknologi informasi di Sekolah Tinggi Teknologi Pagar Alam yang bertujuan untuk mendapatkan penilaian awal dari penerapan tata kelola teknologi informasi bedasarkan COBIT 5 dengan kondisi pelaksanaan yang sedang bejalan untuk meningkatkan nilai dari tata kelola teknologi informasi pada STT Pagar Alam. Pengumpulan data dengan melakukan observasi, wawancara dan kuesioner. Hasil pengelolaan data yang disesuaikan deng an domain COBIT 5 akan dijadikan nilai antar domain. Hasil perhitungan maturity level dari

8 responden pada proses hasil nilai maturity level taat kelola teknologi informasi yang ada di Sekolah Tinggi Teknologi Pagar Alam saat ini menunjukan bahwa 9 domain mengarah pada level 2 (Repeatable) yaitu EDM04, APO01, APO04, APO07, BAI04, BAI10, DSS01, DSS03 dan MEA01. Hasil nilai maturity level saat ini menunjukan bahwa 2 domain mengarah pada level 3 (Defined) yaitu APO03 dan BAI09. Secara umum strategi strategi perbaikan tata kelola teknologi informasi di Sekolah Tinggi Teknologi Pagar Alam maka proses dan kegiatan harus ditetapkan dan didokumentasikan, distandarisasikan dan diintegrasikan bersama.
\end{abstract}

Kata Kunci : Optimalisasi, Tata Kelola TI, Cobit 5, Maturity Level

\section{PENDAHULUAN}

Teknologi informasi sangat penting bagi suatu organisasi karena di percaya dapat membantu meningkatkan proses bisnis suatu organisasi, tidak terkecuali perguruan tinggi. Tata kelola teknologi informasi (IT Governance) merupakan bagian terintegrasi bagi kesuksesan pengaturan perusahaan dengan jaminan efisiensi dan efektivitas perbaikan pengukuran dalam suatu proses perusahaan. Optimalisasi Tata kelola Teknologi Informasi (IT Governance) merupakan cara untuk mengukur pencapaian hasil sesuai harapan berdasarkan tujuan pada Standar Operasional Prosedur. Sekolah Tinggi Teknologi Pagar Alam telah menerapkan penggunaan teknologi informasi sebagai menunjang pelayanan bagi seluruh civitas akademika kampus. Dari beberapa sistem yang telah di implementasikan terdapat permasalahan sistem yang belum adanya Standard Operating Prosedur (SOP), belum terintegrasinya sistem yang digunakan bagi pihak yang berkepentingan seperti dosen, mahasiswa maupun karyawan, Belum adanya penelitian yang dilakukan sebelumnya jadi dari hasil yang sudah di dapat maka akan di lakukan evaluasi lebih lanjut untuk melihat tingkat keoptimalisasiannya. Berdasarkan latar belakang yang telah di jelaskan, peneliti 
berkeinginan mengajukan judul "Optimalisasi Tata Kelola Teknologi Informasi Meng gunakan Cobit 5 (Studi Kasus STT Pagar Alam)".

Berdasarkan latar belakang yang telah dijelaskan sebelumnya, maka dapat diidentifikasikan rumusan masalah yaitu "Bagaimana Optimalisasi Tata Kelola Teknologi Informasi di Sekolah Tinggi Teknologi Pagar Alam". Agar penelitian ini lebih terarah dan tidak menyimpang dari permasalahan yang ada, maka diperlukan adanya batasan masalah sebagai berikut Metode yang akan di pakai menggunakan framework COBIT 5, Penelitian ini menggunakan domain EDM (Evaluate, Direct, dan Monitor), APO (Align, Plan and Organize) dan BAI (Build,Acquire and Implement), DSS (Service and Support) dan MEA (Monitor,Evaluate and Asses). Adapun tujuan penelitian yang di ambil oleh penulis dalam melakukan penelitian ini adalah Mendapatkan penilaian awal dari penerapan tata kelola teknologi informasi berdasarkan COBIT 5 dengan kondisi pelaksanaan yang sedang berjalan, Mendapatkan rencana penggunaan teknologi informasi serta standar prosedur pelaksanaan dalam penggunaannya, Meningkatkan optimalisasi dalam tata kelola teknologi informasi pada kampus.

\section{METODOLOGI PENELITIAN}

\subsection{Desain Penelitian}

Metode penelitian yang digunakan dalam penelitian ini adalah bersifat deskriptif, yaitu hasil penelitian dalam bentuk deskripsi yang meliputi deskripsi kualitatif. Dalam metode penelitian ini, fokus utamanya adalah mencari informasi yang lengkap mengenai penelitian yang akan dilakukan.

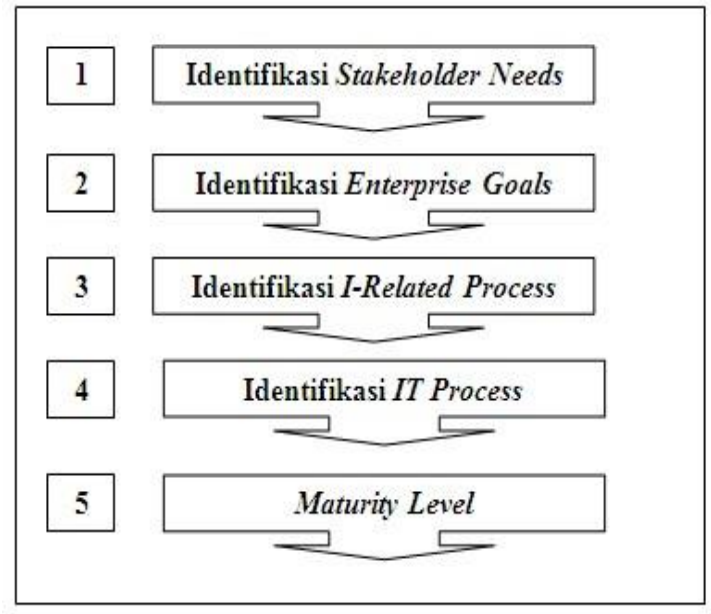

\section{Gambar 2.1 Desain Penelitian}

\subsection{Teknik Pengumpulan Data}

Teknik pengumpulan data yang digunakan pada saat proses penelitian ini adalah terdiri dari :

\section{a. Wawancara}

Pertama yang akan dilakukan dalam mengumpulkan data atau informasi adalah dengan mewawancara ketua UPT Sekolah Tinggi Teknologi Pagar Alam yang dianggap mempunyai wewenangan terhadap tata kelola teknologi informasi yang akan dilakukan. Dari wawancara yang dilakukan agar dapat memperoleh data penelitian secara lisan.

b. Observasi

Teknik pengumpulan data yang kedua observasi, akan dilakukan pengamatan dan pelacakan secara langsung pada objek dan data dari organisasi yang diteliti dalam hal ini adalah STT Pagar Alam, dengan melihat proses yang terjadi saat ini berguna sebagai data awal penelitian dapat dimanfaatkan untuk menggambarkan secara umum keadaan sekarang. 


\section{c. Kuesioner}

Teknik pengumpulan data yang terakhir adalah kuesioner yang akan dilakukan dalam mengumpulkan data atau informasi dengan memberikan daftar pertanyaan ke seluruh admin sistem informasi yang ada pada Sekolah Tinggi Teknologi Pagar Alam. Seperti Website STT Pagar Alam, E-learning, Sistem Akademik, e-library dan SIMASET(Sistem Inventaris Barang), website Prodi. Informan dalam penelitian ini sebanyak 8 orang dimana 1 ketua UPT dan 7 admin sistem informasi yanga di STT Pagar Alam.

Pengumpulan data ini, merupakan kegiatan yang harus dilakukan dalam penelitian, bertujuan untuk mendapatkan data dan informasi yang lengkap untuk kebutuhan penelitian, data-data yang dikumpulkan terdiri dari data sekunder dan data primer.

\section{HASIL DAN PEMBAHASAN}

\subsection{Penilaian Maturity Level}

Didapatkan dengan perhitungan dari rekapitulasi hasil jawaban kuesioner maturity level pada proses EDM04, APO01, APO03, APO04, APO07, BAI04, BAI09, BAI10, DSS01, DSS03, dan MEA01. Berdasarkan hasil dari jawaban kuesioner maturity level, berikut merupakan rekapitulasi dari jawaban kuesioner maturity level tersebut.

Tabel 3.1 Maturity Level

\begin{tabular}{clc}
\hline & \multicolumn{1}{c}{$\begin{array}{c}\text { Proses } \\
\text { Domain }\end{array}$} & $\begin{array}{c}\text { Current } \\
\text { Maturity }\end{array}$ \\
\hline EDM04 & Optimalisasi Sumber Daya & 2,27 \\
\hline APO01 & Menetapkan Rencana Strategis IT & 2,37 \\
\hline APO03 & Menentukan Arah Teknologi & 2,54 \\
\hline APO04 & Menetapkan inovasi (Pembaharuan) & 2,45 \\
\hline APO07 & mengelola Sumber Daya Manusia & 2,16 \\
\hline BAI04 & Mengelola Ketersediaan dan Kapasitas & 2,07 \\
\hline BAI09 & Mengelola Aset & 2,62 \\
\hline BAI10 & Pengelolaan Mengenai Konfigurasi & 2,35 \\
\hline DSS01 & Mengelola Operasional & 1,82 \\
\hline DSS03 & Mengelola Permasalahan & 2,37 \\
\hline \multirow{2}{*}{ MEA01 } & $\begin{array}{l}\text { Memantau, Mengevaluasi dan Menilai Kinerja } \\
\text { dan Kesesuaian }\end{array}$ & 2,4 \\
\hline & \multicolumn{2}{c}{ Rata - rata } \\
\hline
\end{tabular}

Berdasarkan dari hasil kuesioner data yang telah dikelola pada perguruan tinggi STT Pagar Alam pada proses ini dilakukan analisa dari pengoptimalan yang terlihat pada gambar grafik hasil kuesioner berikut ini:

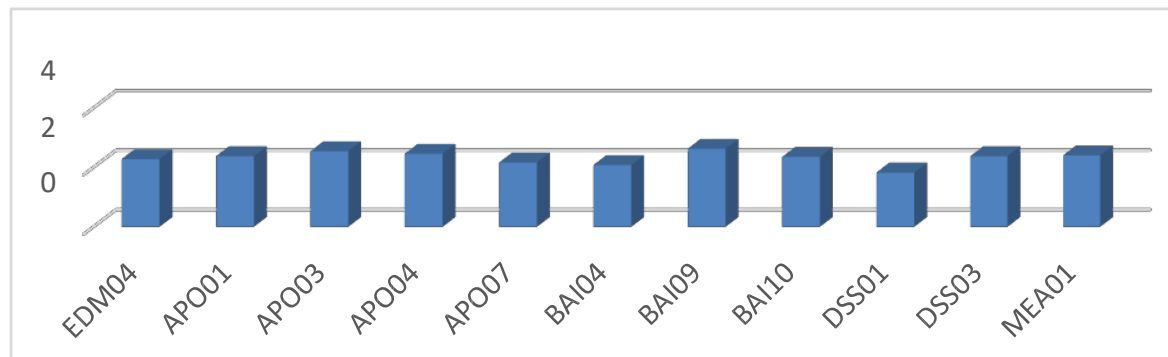

Gambar 3.1 Maturity Level

Berdasarkan hasil rekapitulasi diatas, hasil perhitungan maturity level dari 8 informan pada proses EDM04 mendapatkan indeks 2,27, APO01 mendapatkan indeks 2,37, APO03 mendapatkan indeks 2,54, APO04 
mendapatkan indeks 2,45, APO07 mendapatkan indeks 2,16, BAI04 mendapatkan indeks 2,07, BAI09 mendapatkan indeks 2,62, BAI10 mendapatkan indeks 2,35, DSS01 mendapatkan indeks 1,82, DSS03 mendapatkan indeks 2,37 dan MEA01 mendapatkan indeks 2,4. Total nilai indeks semua domain adalah 2,31 atau berada pada tingkat 2 (Repeatable).

3.2 Analisis Kesenjangan

Analisis tingkat kesenjangan tata kelola teknologi informasi bertujuan untuk memberikan kemudahan perbaikan tata kelola teknologi informasi melalui informasi atribut model kematangan. Dengan demikian akan diketahuo prose proses mana saja yang memiliki kesenjangan dan membutuhkan perbaikan. Analisis kesenjangan dilakukan dengan cara membandingkan secara umum tingkat kematangan tata kelola teknologi informasi yang diharapkan (to-be) dengan tingkat kematangan tata kelola teknologi informasi saat ini (as-is). Dari perbandingan tingkat kematangan tersebut akan diperoleh proses proses mana yang belum sesuai dengan tingkat kematangan yang diinginkan. Analisis kesenjangan seperti tabel 3.2 dibawah ini :

Tabel 3.2 Analisis Kesenjangan

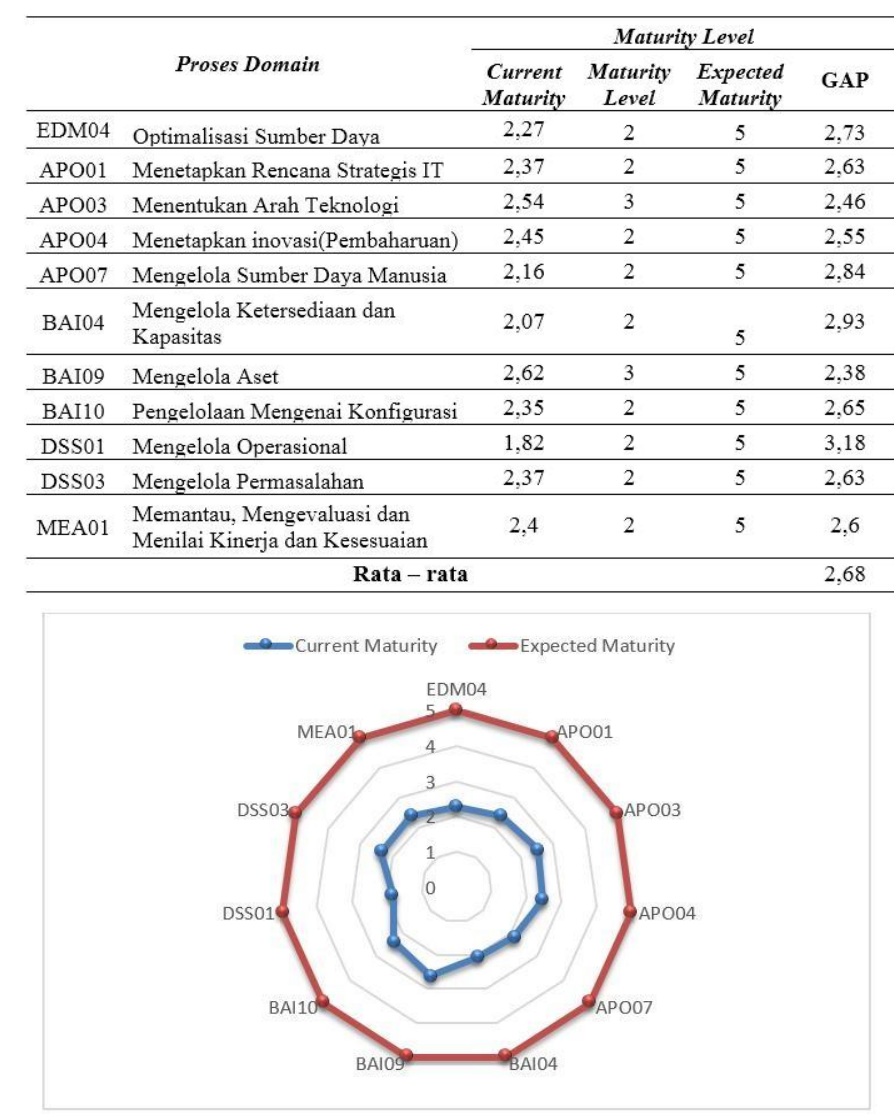

\section{Gambar 3.2 Analisis Kesenjangan}

Pada gambar 3.2 menjelaskan bahwa hasil dari analisis kesenjangan terhadap sebelas proses domain yang diteliti. Nilai rata rata pada analisis kesenjangan ( $g a p$ ) pada seluruh proses domain yang diteliti sebesar 2,68. Sangat dibutuhkan penyesuaian pada masing masing proses domain tersebut. Maka peneliti akan memberikan rekomendasi pada tiap proses yang diteliti, sehingga rekomendasi perbBaikan yang diberikan tepat. 


\section{KESIMPULAN}

4.1 Kesimpulan

Berdasarkan penelitian yang dilakukan, peneliti dapat menyimpukan sebagai berikut :

1. Mendapatkan hasil penelitian awal bahwa nilai current maturity dari sebelas domain tersebut adalah EDM04 (2,27), APO01 (2,37), APO03 (2,54), APO04 $(2,45)$, APO07 $(2,16)$ BAI04 $(2,07)$, BAI09 $(2,62)$, BAI10 $(2,35)$, DSS01 $(1,82)$, DSS03 $(2,37)$ dan MEA01 $(2,4)$. Nilai rata rata dari keseluruhan domain adalah 2,31 .

2. Hasil nilai maturity level taat kelola teknologi informasi yang ada si Sekolah Tinggi Teknologi Pagar Alam saat ini menunjukan bahwa 9 domain mengarah pada level 2 (Repeatable) yaitu EDM04, APO01, APO04, APO07, BAI04, BAI10, DSS01, DSS03 dan MEA01. Hasil nilai maturity level saat ini menunjukan bahwa 2 domain mengarah pada level 3 (Defined) yaitu APO03 dan BAI09.

3. Secara umum strategi strategi perbaikan tata kelola teknologi informasi di Sekolah Tinggi Teknologi Pagar Alam maka proses dan kegiatan harus ditetapkan dan didokumentasikan, distandarisasikan dan diintegrasikan bersama.

\subsection{Saran}

Berdasarkan hasil penelitian yang telah dilakukan, maka peneliti memberikan beberapa rekomendasi sebagai berikut :

1. Adapun Sekolah Tinggi Teknologi Pagar Alam harus melaksanakan Perencanaan, pengevaluasian, pendokumentasian dan pengontrolan terhadap IT dan perlu dilakukan secara terjadwal atau rutin.

2. Diharapkan penelitian selanjutnya untuk mengambil jangkauan domain yang lebih banyak lagi serta disesuaikan dengan permasalahaan untuk dicarikan solusinya.

Referensi :

Abdul Hakim, H. S. (2014). Evaluasi Tata Kelola Teknologi Informasi Dengan Framework COBIT 5 di Kementrian ESDM. Journal of Information System , 106.

Ali, M. A. (2014). Analisis Optimalisasi Pelayanan Komsumen Berdasarkan Teori Antrian Pada KALTIMGPR.COM di Samarinda. eJurnal Ilmu Administrasi Bisnis , 348 .

Asriyanik, M. H. (2017). Tata kelola teknologi informasi pada perguruan tinggi menggunakan control objective for information \& related technology (COBIT) 5 . Teknik Informatika dan Sistem Informasi , 206.

Aufa Salsabila, H. P. (2017). Analisi Tingkat Kematangan Sistem Informasi Pada Rumah Sakit Aisyiyah Kudus. Sistem informasi , 6.

Christianto, J. F. (2017). Audit Menggunakan COBIT 4.1 dan COBIT 5 dengan Study Case. Jakarta: Teknosain.

Fransiskus Adikara, S. (2016). Optimalisasi Sumber Daya Teknologi Informasi Domain EDM 04.02 Pada Lembaga Pendidikan Dengan Menggunakan Framework COBIT 5. Abdimas, 18.

Hadi Hilmawan, O. D. (2015). Analisis Tata Kelola Teknologi Informasi Menggunakan Kerangka Kerja COBIT 5 pada AMIK JTC Semarang. Teknologi dan Sistem Komputer , 247 DAN 248.

Mariana, A. P. (2011). Analisis Tata Kelola Teknologi Informasi (IT Governanace) pada Bidang Akademik dengan Cobit Frame Work Studi Kasus pada Universitas Stikubank Semarang. Teknologi Informasi DINAMIK, 139.

Prof. Dr. Jogiyanto HM, M. A. (2008). Sistem Teknologi Informasi. Yogyakarta: Andi. 
Putri, R. E. (2016). Penilaian KapabilitasProses Tata Kelola TI Berdasarkan Proses DSS01 Pada Framework COBIT 5. CoreIT , 42,43,44.

Sasongko, N. (2009). Pengukuran Kinerja Teknologi Informasi Menggunakan framework COBIT Versi 4.1 ping test dan CAAT pada PT.Bank X Tbk di Bandung`. Seminar Nasional Aplikasi Teknologi Informasi, 109.

Sucahyo, D. F. (2015). Audit Sistem Informasi/ Teknologi Informasi Dengan Kerangka Kerja COBIT untuk Evaluasi manajemen Teknologi Informasi Di Universitas XYZ. Jurnal Sistem Informasi MTI-UI, 37.

Sugiyono. (2014). Metode Penelitian Kuantitatif, Kualitatif dan R\&D. Bandung: Alfabeta.

Sugiyono, P. (2013). Metode Penelitian Kuantitatif Kualitatif dan R\&D. Bandung: Alfabeta.

Supradono, B. (2011). Tingkat Kematangan Tata Kelola Teknologi Informasi (IT Governance) pada Layanan dan Dukungan teknologi Informasi (Kasus: Perguruan Tinggi Swasta Di Kota Semarang). Seminar Nasional Teknologi Informasi dan Komunikasi Terapan ISBN 979-26-0255-0 , 2.

Triwahyuni, A. K. (2003). Pengenalan Teknologi Informatika. Yogyakarta: Andi.

Yuliar, S. (2009). Tata kelola teknologi. Bandung: 2009. 